\title{
A Novel Mutation in the GJB2 (Connexin 26) Gene in Egyptian Children with Non-syndromic Sensorineural Hearing Loss
}

\author{
Nagwa Meguid ${ }^{1}$, Motaza Omran ${ }^{2}$, Iman Ghorab $^{3}$, Ahmed Dardir $^{1}$, Ehab Ragaa ${ }^{1}$, Suzette Helal ${ }^{1}$, Mona Anwar ${ }^{1}$ \\ ${ }^{1}$ National Research Center - Research on Children with Special Needs Department, Giza, Egypt; ${ }^{2}$ National Research Center \\ - Biomedical Technology, Giza, Egypt; ${ }^{3}$ Hearing and Speech Institute - Department of Audiology, Giza, Egypt
}

\author{
Citation: Meguid N, Omran M, Ghorab I, Dardir \\ A, Ragaa E, Helal S, Anwar M. A Novel \\ Mutation in the GJB2 (Connexin 26) Gene in \\ Egyptian Children with Non-syndromic \\ Sensorineural Hearing Loss. Maced J Med Sci. \\ 2013 June 15; 6(2):141-145 \\ http://dx.doi.org/10.3889/MJMS.1857-5773.2013 \\ .0287 \\ Key words: connexin 26; autosomal \\ recessive; nonsyndromic hearing loss; \\ mutation; Egyptians. \\ "Correspondence: Dr. Nagwa Meguid. Nationa \\ Research Centre - Research on children with \\ special needs, National Research Centre, El- \\ Bohoth Street- El Dokki, Cairo 12311, Egypt. \\ Fax:0020233370931. \\ E-Mail:meguidna@yahoo.com \\ Received: 23-Jan-2013; Accepted: 05-Mar- \\ 2013; Online first: 20-Mar-2013 \\ Copyright: @ 2013 Meguid N. This is an open- \\ access article distributed under the terms of \\ the Creative Commons Attribution License, \\ which permits unrestricted use, distribution, \\ and reproduction in any medium, provided the \\ Competing Interests: The authors have \\ declared that no competing interests exist.
}

\begin{abstract}
This study aimed to investigate the frequency of any novel gene mutations, in human GJB2 gene among Egyptians with familial sensorineural non-syndromic hearing impairment.

PCR amplifying the entire coding region of GJB2 gene and direct DNA sequencing to analyze mutations in this gene among 78 cases with autosomal recessive congenital non syndromic hearing loss was used.

We describe for the first time a novel mutation in the coding region of the GJB2 gene. A deletion mutation of $T$ at position 59 , in the intracellular domain of connexin 26 , resulting in a frameshift at the $20^{\text {th }}$ amino acid leading to a premature termination of the protein was detected in $9 \%$ of the studied cases.

These data provide a novel molecular explanation for the role of GJB2 mutation in hearing loss to be taken into consideration in the genetic diagnosis and counseling of non-syndromic sensorineural hearing loss in Egyptians.
\end{abstract}

\section{Introduction}

Hearing loss is the most common sensory deficit in humans and most auditory system dysfunctions resulting in hearing loss are genetically inherited [1]. It affects approximately 10 per cent of the world population, which is significant enough to compromise the development of normal language skills and social development. It can appear at any age with varying degrees of severity [2].

Over 100 loci, both nuclear and mitochondrial, are already implicated in the development of this most common sensory disorder of humans [3].

GJB2 (Gap Junction protein $\beta$ Type 2), encodes Connexin 26 (Cx26), a member of a highly conserved protein family found throughout the animal kingdom [4]. Six connexins oligomerize to form porelike plasma membrane hemichannels called connexons, they form gap junction channels which facilitate electrical and biochemical coupling between cells. Ultrastructural studies have identified two gap junction networks, including that of the epithelial tissue and that of the connective tissue, in the mammalian cochlear duct and vestibular system [5]. The gap junction system is the most likely pathway for cochlear $\mathrm{K}+$ recirculation following hair cell depolarization maintaining cochlear homeostasis [6].

The GJ channels have diverse functions, including electrical signal propagation, metabolic cooperation, growth control, spatial buffering of ions, and cellular differentiation [7]. Mutations in one gene, 
GJB2 are responsible for more than half of all cases of recessive non-syndromic deafness [8].

The mutation spectra of this gene vary among different ethnic groups. The greatest problem for the genetic diagnosis of hearing impairment is the high genetic heterogeneity of this disorder. Because of the high frequency of GJB2 mutations, mutation analysis of this gene is widely available as a diagnostic test. Certain Cx26 gene mutations are ethnic-specific such as, 35delG mutation prevalent in Caucasians, R143W in Ghana, 167delT in Ashkenazi Jews, 235delC in Orientals and W24X in Indians [9]. In all these populations, Cx26 gene mutations were highly observed in heterozygous condition, which proves the heterogeneity of non syndromic hearing impairment.

The 35delG mutation, which accounts for the majority of GJB2 mediated hearing loss among Caucasians, is a deletion of a single guanine residue $(\mathrm{G})$ in a stretch of $6 \mathrm{Gs}$ at nucleotide position 30-35 of the coding region of the GJB2 gene. This single deletion shifts the reading frame, resulting in a premature chain termination product comprising only 12 amino acids. The $35 \mathrm{delG}$ mutation in GJB2 gene among Egyptians with recessive nonsyndromic congenital sensorineural hearing impairment was studied and revealed that $10.17 \%$ had deletion of $\mathrm{G}$ at position 35 [10].

Understanding the underlying causes of the variability in GJB2 gene is of major importance in terms of genetic counseling. The purpose of this study was to investigate the frequency of any novel gene mutations, other than $35 \mathrm{delG}$, in human GJB2 gene among Egyptian children with familial sensorineural non-syndromic hearing impairment.

\section{Patients and Methods}

\section{Studied Population}

Seventy eight Egyptian children (38 males and 40 females) with prelingual non-syndromic hearing loss were enrolled in this study. Their ages ranged between 1 to 15 years. Parental consanguinity was present in all studied families (34 families). All patients were recruited from the genetic counseling service for deaf people at the Clinic of Children with Special Needs, National Research Center, and the outpatient clinic of the Hearing and Speech Institute, Cairo, Egypt.

The study was approved by the Ethics Committee of The National Research Center, Cairo, Egypt, and written informed consent was obtained from all parents or caregivers. All cases were subjected to the following:

1. Detailed history was taken for each patient that included: Parental consanguinity, family history of similar condition, pregnancy history, perinatal history, history of drug intake, recurrent ear infections, ear trauma, and history of any chronic illness. Onset, course and duration of the hearing loss were obtained.

2. Three generations pedigree was constructed for each case.

3. Careful clinical examination had been done to exclude syndromic deafness, and other associated anomalies.

4. Ear, nose and throat (ENT) examination had been carried out to check for any ear malformations, signs of trauma or scars of previous operations.

5. Full audiological assessment: Auditory brain stem response $(A B R)$ for cases $\leq 4$ years old and puretone audiometry (PTA) for cases $>4$ years old to determine the degree of hearing for both ears.

\section{Molecular Analysis}

Genomic DNA Extraction: Five $\mathrm{ml}$ venous blood was obtained from each patient in a sterile tube containing EDTA as an anticoagulant for genomic DNA extraction. Extraction was carried out by using a ready-made QIAGEN kit (QIAamp DNA Mini kit and, QIAGEN; Germany). Genomic DNA was diluted 1:100 in TE buffer and the A260 absorbance was read and the concentration was calculated.

DNA amplification using polymerase Chain Reaction (PCR): Amplification of the connexin 26 (Cx 26) coding region was achieved by using the following primers:

Forward Primer: 5' tct ttt cca gag caa acc gc 3'

Reverse Primer: 3'act cgt gcc caa cgg agt ag 5'

$\mathrm{PCR}$ reaction was performed in a final volume of $50 \mu \mathrm{l}$, containing $200 \mathrm{ng}$ genomic DNA, 10mM Tris$\mathrm{HCl}\left(\mathrm{pH} 9.0\right.$ at $\left.25^{\circ} \mathrm{C}\right), 50 \mathrm{mM} \mathrm{KCl}$ and $0.1 \%$ Triton $^{\circledR} \mathrm{X}$ 100, $1.5 \mathrm{mM} \mathrm{MgCl} 2,200 \mu \mathrm{M}$ dNTPs, $10 \mu \mathrm{M}$ of each primer and 2.5 units of Taq polymerase (PromegaUSA). Then the thermal cycler was programmed according to the following steps to undergo the amplification reaction for $\mathrm{C} \times 26$ gene coding region. First; samples were denatured at $94{ }^{\circ} \mathrm{C}$ for 5 minutes. Subsequently; 40 cycles of denaturation were achieved at $94{ }^{\circ} \mathrm{C}$ for 15 seconds, annealing was carried out at $55^{\circ} \mathrm{C}$ for 30 seconds and extension was done $72^{\circ} \mathrm{C}$ for 1 minute, followed by 5 minutes of post extension.

DNA Purification: Amplified fragments on agarose gel were purified by using a ready-made extraction kit (Invisorb® Spin DNA, Invitek; Germany).

Sequencing: Direct DNA sequencing was carried out in both directions using the forward and reverse primers on the Automated Sequencer "ABI Prism 310 Genetic Analyzer". The cycle-sequencing reaction was performed in a volume of $20 \mu \mathrm{l}$ containing: $8 \mu \mathrm{l}$ of the terminator ready reaction mixture 3.2 pmole of either the forward primer or the reverse primer and $30 \mathrm{ng}$ of purified PCR product. 
The thermal cycling protocol was followed on the "Perkin Elmer, Gene Amp PCR System $9700^{\circ}$; $95^{\circ} \mathrm{C}$ for 5 minutes followed by 25 cycles of $\left(96^{\circ} \mathrm{C}\right.$ for 10 seconds, $50^{\circ} \mathrm{C}$ for 5 seconds and $60^{\circ} \mathrm{C}$ for 4 minutes). Centri-Sep Columns (Princetion Separations, Philadelphia) were used for effective and reliable removal of excess Dye Deoxy ${ }^{\mathrm{TM}}$ terminators from completed DNA sequencing reactions. Data were compared and aligned with different sequences of different strains using the Clustal W software for multiple alignments http://www.genome.JP/tools /clustal.

Table 1: Different strains that showing alignment with the coding sequence of $\mathrm{C} \times 26$ gene in Egyptian patients.

gi/33391196/gb/AY28097.1/Homo sapiens connexin 26 (GJB2) gi/30584772/gb/BT007967.1/Synthetic construct Homo sapiens gi/30582302/gb/BT006732.1/Homo sapiens gap junction protei gi/9944124/emb/AL138688.27/Human DNA sequence from clone $R$ gi/19401866/gb/AF479776.1/Homo sapiens connexin 26 (GJB2) gi/16877591/gb/BC017048.1/Homo sapiens gap junction protei.. gi/42558282/ref/NM_004004.3/Homo sapiens gap junction prot gi/9652206/gb/AF/281280.1/AF281280/Homo sapiens gap junction gi/30720309/gb/AY255853.1/Homo sapiens mutant connexin 26 gi/4481752/gb/M86849.2/HUMGPJUNC/Homo sapiens connexin 26 gi/40254836/ref/NM_006783.2/Homo sapiens gap junction prot gi/24660316/gb/BC038934.1/Homo sapiens gap junction protei gi/22761210/dbj/AK075247.1/Homo sapiens cDNA FLJ90766 fis gi/11544493/emb/AL355984.11/Human DNA sequence from clone gi/15277748/gb/BC012918.1/Homo sapiens gap junction protei gi/30268297/emb/AL832611.2/HSM803921/Homo sapiens mRNA; cDN gi/22779876/ref/NM_021954.2/Homo sapiens gap junction prot gi/5381288/gb/AF075290.1/AF075290/Homo sapiens gap-junction gi/12803916/gb/BC002805.1/Homo sapiens gap junction protel gi/24660121/gb/BC039198.1/Homo sapiens gap junction protei gi/18490872/gb/BC022426.1/Homo sapiens gap junction prote

\section{Results}

We studied 78 Egyptian patients with prelingual non-syndromic hearing loss. Parental consanguinity was present in all studied families (34 families). Forty eight cases $(61.5 \%)$ had severe hearing loss, 16 cases $(20.5 \%)$ showed moderate hearing loss and 14 cases $(17.9 \%)$ had mild hearing loss.

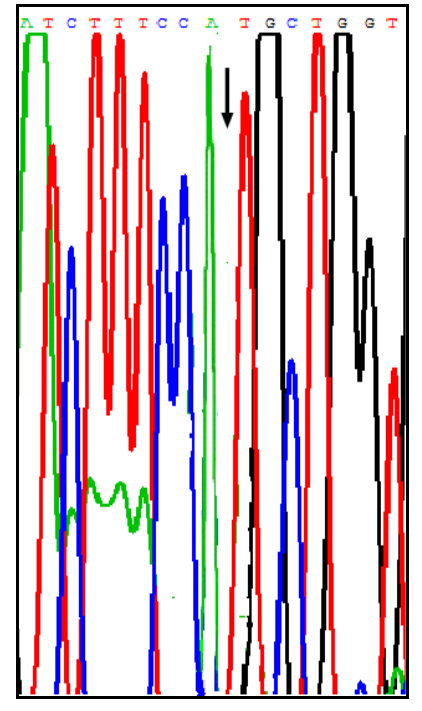

Figure 1: The sequence of a novel deletion frameshift mutation. An arrow indicates the mutation site (Deletion of $T$ at bp 59).
After direct sequencing of all samples using the primers in both directions, forward and reverse primers, the obtained sequence was aligned with human $\mathrm{Cx} 26$ gene on $\mathrm{NCBI}$ database revealing a novel GJB2 deletion frameshift mutation (Figure 1) in 3 out of 34 families.

A novel mutation was detected, which was the deletion of $T$ at position 59 resulting in a frameshift at the $20^{\text {th }}$ amino acid, leading to a premature termination of the protein (Table 2). The mutation was segregated in the family according to a recessive mode of inheritance. No other homozygous loss-offunction mutation segregating with affected status was identified in other family members. This variant was not present in more than 150 ethnically-matched, healthy, in our in-house dataset. The sequence is shown in the reverse direction. All patients with the novel mutation showed severe hearing loss.

Table 2: A novel mutation in Cx26 gene in Egyptian patients with non-syndromic sensorineural hearing loss.

\begin{tabular}{lllll}
\hline $\begin{array}{l}\text { Nucleotide } \\
\text { Change }\end{array}$ & Effect & $\begin{array}{l}\text { Type of } \\
\text { Mutation }\end{array}$ & $\begin{array}{l}\text { Protein } \\
\text { Domain }\end{array}$ & $\begin{array}{l}\text { No. of } \\
\text { Patients }\end{array}$ \\
\hline $\begin{array}{l}\text { Del of T at } \\
\text { position } 59\end{array}$ & $\begin{array}{l}\text { Stop } \\
\text { Codon } \\
\text { (Term.) }\end{array}$ & Framshift & IC1 & $\begin{array}{l}\text { 3 out of } 34 \\
\text { families }(7 / 78 \\
\text { cases, } 9 \%) .\end{array}$ \\
\hline
\end{tabular}

\section{Discussion}

Deafness is a worldwide prevalent disease that seriously impairs human quality of life. The deafness-associated gene mutation spectrum as well as dominant gene profile varies greatly among regions and races [11]. 35de1G, 167de1T, and 235de1C are reported to be the most prevalent mutant genes among Caucasian, Jewish, and Asian populations, respectively [12-14]. Contemporary studies of the causes of congenital and early-onset deafness have incorporated the tools of genetic epidemiology, including molecular testing, to identify a growing number of potential genetic and environmental causes.

In most cases, inherited HL is monogenic. In $70 \%$ of neonates who fail newborn hearing screens and are presumed to have inherited $\mathrm{HL}$, there are no other distinguishing physical findings and the $\mathrm{HL}$ is classified as nonsyndromic. In the remaining $30 \%$, the $\mathrm{HL}$ is accompanied by other physical findings and is said to be syndromic [15]. Of the more than 400 syndromes in which $\mathrm{HL}$ is a recognized feature, Usher syndrome, Pendred syndrome and Jervell and LangeNielsen syndrome are the most frequent [16]. Monogenic hearing loss can be inherited in different ways. Autosomal recessive HL (ARNSHL) occurs in $80 \%$ of cases and is typically prelingual, while autosomal dominant HL (ADNSHL) accounts for about $20 \%$ of cases and is most often postlingual. In less than $1 \%$ of cases, the inheritance occurs through the $\mathrm{X}$-chromosome or the mitochondria [17]. Monogenic hearing loss is an extremely heterogeneous trait, with 
over 100 mapped loci and 46 causally implicated genes (Hereditary Hearing Loss Homepage; http://webh01.ua.ac.be/hhh/).

The important role of intercellular communication via gap junctions has been confirmed by findings that certain $C X$ gene mutations, particularly those of GJB2 and GJB6, cause hearing loss [18].

Gap junctions (GJs) are the only known intercellular channels linking the cytoplasm of adjacent cells. They facilitate intercellular exchanges of ion, metabolite and signaling molecules. GJs in all vertebrates are assembled from connexins (Cxs). Connexins are small transmembrane proteins that belong to an extensive protein family found in most metazoans. Six connexins can oligomerize to form a hemichannel (connexon) in the cell membrane [4]. The Cx gene family has twenty-one members in human genome [19]. New information on the physiological roles of vertebrate connexins has emerged from genetic studies. Mutations in connexin genes underlie a variety of human diseases, including deafness, demyelinating neuropathies, and lens cataracts [20].

To date, more than 154 GJB2 mutations have been identified in the coding exon of GJB2 (http://davinci.crg.es/deafness), but a single chaintermination mutation, $35 \mathrm{delG}$, accounts for up to $70 \%$ of pathologic alleles in many populations. Although this mutation is common in Western Europe and the Middle East [21], much lower frequencies have been observed in Asia [22]. The 35delG mutation exhibits linkage disequilibrium, and haplotype analysis suggested that it arose from a single individual in the Middle East approximately 10,000 years ago [23].

The GJB2 mutation spectrum diverges substantially among populations, as reflected by specific ethnic biases for common mutations like $235 \mathrm{delC}$ in the Japanese (carrier rate of 1\%-2\%) [24], 167 delT in the Ashkenazi Jewish population (carrier rate of $7.5 \%$ ) [25], V37I in Taiwan (carrier rate of $11.6 \%$ ) [26], R143W in Ghana and W24X in Indians [9]. Despite this variability, the combined frequency of all GJB2 mutations is sufficiently high in most populations to make mutation analysis of this gene a clinically useful, and therefore widely available, genetic test. Among the Caucasians, populations of Slovak Romany, Italy and Northeastern Hungary show very high rate of $\mathrm{Cx} 26$ mutations. On the contrary, relatively low frequency rate was observed in a few African populations; Kenya (2\%) and Sudan (7\%) while high frequencies in Tunisia (17\%) [2].

In Egypt, Meguid et al. (2008) [10] reported that the frequency of $35 \mathrm{delG}$ mutation in GJB2 gene among cases with recessive nonsyndromic congenital sensorineural hearing impairment was $10.17 \%$. All cases were homozygous for the mutation. Compared to other populations, $35 \mathrm{del}$ mutation comprised a lower frequency among Egyptians which confirms the genetic heterogeneity and ethnic variation of nonsyndromic sensorineural hearing impairment. They stated that audiological evaluation of cases with 35delG mutation revealed that severe hearing loss was detected in $66.7 \%$ of cases, and moderate hearing loss in $33.3 \%$. In the present study, we aimed to characterize the mutation profiles, of 78 patients with autosomal recessive nonsyndromic hearing loss in Egypt to find out any other novel mutations. The entire coding region of the GJB2 gene was directly sequenced in all patients.

We describe for the first time a new mutations in GJB2 gene, which also has not been previously described, is a deletion of $\mathrm{T}$ at position 59 (c.59delT), in the intracellular domain of connexin 26 among $9 \%$ of the studied cases, resulting in a frameshift at the $20^{\text {th }}$ amino acid, leading to a premature termination of the protein that would severely disrupt the protein structure.

The structure and function of human connexins have been extensively studied at the biochemical and physiological levels. Studies of mutant forms of connexin have preceded their connection to human disease. Site-directed mutagenesis and domain replacement forms of human Cx26 have aided in the definition of important and essential elements of connexin primary structure [27]. Connexins contain four transmembrane domains (TM1-TM4), two extracellular domains (EC1-EC2), one cytoplasmatic loop (CL), and $\mathrm{N}$ - and $\mathrm{C}$ cytoplasmic termini (NT-CT). The N-terminal domain is involved in the process of membrane integration and hexamer formation [28] and, together with the first transmembrane domain, determines voltage gating. The extracellular loops regulate the connexonconnexon interactions, including heterotypic channel formation. Each loop contains three cysteine residues, conserved across all connexins and that form essential intramolecular disulfide bonds [29]. The intracellular loop and C-terminal domains regulate $\mathrm{pH}$ gating [30]. The TM domains are important for protein folding.

Many HI-causing mutations of GJB2 gene have been reported in the connexin-deafness database (http://davinci.crg.es/deafness/). However, after reviewing the literature, our described novel mutation had not been previously identified for cases with autosomal recessive nonsyndromic hearing loss. One novel mutation at position 59 (c.59T>C) affecting a highly conserved residue within the $\mathrm{N}$-terminal domain of GJB2, was previously described in an adult with apparently sporadic congenital HL in Austria [31]. These findings may indicate that this site is a mutational hot spot.

Summing up, in addition to the 35delG mutation which was previously reported to occur in almost $10.17 \%$ of Egyptian individuals suffering from $\mathrm{HL}$ [10], this study emphasises the importance of GJB2 gene mutations in inherited cases of nonsyndromic sensorineural hearing loss in Egypt. A 
novel mutation was identified. The characterization of novel mutant alleles may contribute to a better understanding of the function of the connexin 26 domains. Moreover, these data show the importance of further investigations and future genetic counseling for GJB2 gene mutations.

\section{References}

1. Apps SA, RankinWA, Kurmis AP. Connexin26 mutations in autosomal recessive deafness disorders: A review. International Journal of Audiology. 2007; 46: 75-81.

2. Lingala HB, Sankarathi, Penagaluru PR. Role of connexin 26 (GJB2) \& mitochondrial small ribosomal RNA ( $m t$ 12S rRNA) genes in sporadic \& aminoglycoside-induced non syndromic hearing impairment Indian. Journal of Medical Research. 2009;130: 369-378.

3. Hilgert N, Smith RJ, Van Camp G. Function and expression pattern of nonsyndromic deafness genes. Current Molecular Medicine. 2009 9: 546-564.

4. van Steensel MA. Gap junction diseases of the skin. Am J Med Genet C Semin Med Genet. 2004;131C(1):12-9. Review. Erratum in: Am J Med Genet C Semin Med Genet. 2006;142(1):58

5. Kikuchi T, Kimura RS, Paul DL, Adams JC. Gap junctions in the rat cochlea: immunohistochemical and ultrastructural analysis. Anatomy and Embryology.1995; 191:101-118.

6. Spicer SS, Schulte BA. Evidence for a medial K+ recycling pathway from inner hair cells. Hearing Research.1998;118: 112.

7. Wang WH, Liu YF, Su CC, Su MC, Li SY. A Novel Missense Mutation in the Connexin30 Causes Nonsyndromic Hearing Loss. PLoS ONE. 2011;6(6):e21473.

8. Dalamón $V$, Lotersztein $V$, Béhèran $A$, et al. GJB2 and GJB6 Genes: Molecular Study and Identification of Novel GJB2 Mutations in the Hearing-Impaired Argentinean Population Audiology and Neurotology. 2009;15(3):194-202.

9. Alvarez A, del Castillo I, Villamar M, et al. High prevalence of the W24X mutation in the gene encoding Connexin-26 (GJB2) in Spanish Romani (Gypsies) with autosomal recessive nonsyndromic hearing loss. American Journal of Medical Genetics. 2005 ;137: 255-8.

10. Meguid NA, Motaza H Omran, Ahmed A Dardir, et al.Study of 35delG in Congenital Sensorineural non-syndromic Hearing Loss in Egypt. Journal of Applied Sciences Research. 2008 4(6): 621-626

11. Usami S, Wagatsuma M, Fukuoka $\mathrm{H}$, et al. The responsible genes in Japanese deafness patients and clinical application using Invader assay. Acta Oto-Laryngologica. 2008; 128:446454.

12. Ohtsuka A, Yuge I, Kimura S, et al.GJB2 deafness gene shows a specific spectrum of mutations in Japan, including a frequent founder mutation. Human Genetics. 2003; 112:329 333.

13. Snoeckx RL, Huygen PL, Feldmann D, et al.GJB2 mutations and degree of hearing loss: a multicenter study. American Journal of Human Genetics. 2005;77:945-957.

14. Kenneson A, Van Naarden Braun K, Boyle C. GJB2 (connexin 26) variants and nonsyndromic sensorineural hearing loss: a Huge review. Genetics in Medicine. 2002; 4; 258-274

15. Van Camp G, Willems PJ, Smith RJ. Nonsyndromic hearing impairment: unparalleled heterogeneity. American Journal Human Genetics. 1997; 60:758-764.
16. Toriello HV, Reardon W, Gorlin RJ. Hereditary Hearing Loss and its Syndromes. Oxford University Press, Inc: Oxford, 2004.

17. Cryns K, Van Camp G. Deafness genes and their diagnostic applications. Audiology and Neurotology. 2004; 9:2- 22.

18. Nick R, Forge A, Jagger D. Connexin in the Inner Ear. In Harris A, Locke D, eds. Connexin: A Guide, Humana Press, Springer, USA, 2009: 419-434.

19. Willecke K, Eiberger J, Degen J, et al. Structural and functional diversity of connexin genes in the mouse and human genome. Biological Chememistry. 2002;383:725-737.

20. White TW, Paul DL. Genetic diseases and gene knockouts reveal diverse connexin functions. Annual Review of Physiology. 1999; 61:283-310.

21. Orzan E, Polli R, Martella M, et al. Molecular genetics applied to clinical practice: The $\mathrm{Cx} 26$ hearing impairment. British Journal of Audiology. 1999; 33:291-295.

22. Ram Shankar M, Girirajan S, Dagan O, et al. Contribution of connexin26 (GJB2) mutations and founder effect to nonsyndromic hearing loss in India. Journal of Medical Genetics. 2003; 40(5):e68.

23. Tekin M, Akar N, Cin S, et al. Connexin 26 (GJB2) mutations in the Turkish population: implications for the origin and high frequency of the 35delG mutation in Caucasians. Human Genetics 2001;108:385-389.

24. Abe S, Usami S, Shinkawa H, Kelley PM, Kimberling WJ. Prevalent connexin 26 gene (GJB2) mutations in Japanese. Journal of Medical Genetics. 2000; 37:41-43.

25. Morell RJ, Kim HJ, Hood LJ, et al. Mutations in the connexin 26 gene (GJB2) among Ashkenazi Jews with nonsyndromic recessive deafness. New England Journal of Medicine. 1998; 339:1500-1505

26. Hwa HL, Ko TM, Hsu CJ, et al.Mutation spectrum of the connexin 26 (GJB2) gene in Taiwanese patients with prelingual deafness. Genetics in Medicine. 2003; 5:161-165.

27. Ek JF, Delmar M, Perzova R, Taffet SM. Role of histidine 95 on $\mathrm{pH}$ gating of the cardiac gap junction protein connexin 43 . Circulation Research. 1994; 74:1058-1064.

28. Zeilinger $C$, Steffens $M$, Kolb HA. Length of C-terminus of rCx46 influences oligomerization and hemichannel properties. Biochimica et Biophysica Acta. 2005; 1720: 35-43.

29. Dahl G, Werner R, Levine E \& Rabadan-Diehl C. Mutational analysis of gap junction formation. Biophys J. 1992;62: 172180

30. Bruzzone R, White TW, Paul DL. Connections with connexins: the molecular basis of direct intercellular signaling. European Journal of Biochemistry. 1996; 15: 1-27.

31. Löffler J, Nekahm D, Hirst-Stadlmann A, et al. Sensorineural hearing loss and the incidence of Cx26 mutations in Austria. European Journal of Human Genetics. 2001; 9(3):226-30 